\title{
RELACIONAMENTOS PESSOAIS E SOCIAIS: AMIZADE EM ADULTOS ${ }^{1}$
}

\author{
Luciana Karine de Souza* \\ Claudio Simon Hutz
}

\begin{abstract}
RESUMO. A amizade é um relacionamento importante para o desenvolvimento social, emocional e cognitivo; no entanto a maioria dos estudos trata da amizade na infância e na adolescência, havendo pouca ênfase na investigação de adultos. $O$ presente trabalho apresenta uma revisão da literatura sobre relacionamentos de amizade na adultez, procurando descrever criticamente a produção científica na área. Estudos brasileiros indicam que relacionamentos de amizade no nosso país podem ser comparados aos de outras culturas e discutidos com base nos modelos teóricos existentes. Não obstante, há algumas diferenças que requerem mais estudo, inclusive para verificar se os modelos internacionais correntes são satisfatórios para explicar adequadamente relações de amizade entre adultos na cultura brasileira.
\end{abstract}

Palavras-chave: relacionamento, amizade, adulto.

\section{PERSONAL AND SOCIAL RELATIONSHIPS: FRIENDSHIP IN ADULTS}

\begin{abstract}
Friendship is an important relationship for social, emotional and cognitive development. However, most empirical studies investigate friendship in childhood and adolescence, with little emphasis in adulthood. Current analysis presents a critical review of the literature on friendship among adults, describing the major empirical studies undertaken up to the present. Brazilian studies suggest that friendship among Brazilians might be similar to friendship in other cultures and that international theoretical models may be useful to describe it. Nevertheless, there may be some differences that require further investigation to assess if current models may explain satisfactorily friendship in Brazilian culture.
\end{abstract}

Key words: Relationship, friendship, adult.

\section{RELACIONAMIENTOS PERSONALES Y SOCIALES: AMISTAD EN ADULTOS}

RESUMEN. La amistad es un relacionamiento importante para el desarrollo social, emocional y cognitivo, pero la mayor parte de los estudios trata de la amistad en la niñez y en la adolescencia, habiendo poca énfasis en la investigación con adultos. El estudio en cuestión presenta una revisión de la literatura sobre relacionamentos de amistad en la edad adulta, buscando describir críticamente la producción científica en el área. Estudios brasileños indican que relacionamientos de amistad en ese país pueden ser comparados a los de otras culturas y discutidos en base a los modelos teóricos existentes. Sin embargo, hay algunas diferencias que requieren más estudio incluso para averiguar si los modelos internacionales actuales son satisfactorios para explicar adecuadamente relaciones de amistad entre adultos en la cultura brasileña.

Palabras-clave: Relacionamiento, amistad, adulto.

São poucos os estudos brasileiros sobre amizade na adultez. Em contraste, a amizade infantil e adolescente tem recebido maior atenção (Daudt, Souza \& Sperb, 2007; Garcia, 2005; Lisboa \& Koller, 2003). A ausência de produção científica sistemática sobre a amizade em adultos reflete uma tendência na pesquisa psicológica de priorizar crianças e adolescentes (Souza, Gauer \& Hutz, 2004). Esta revisão de literatura discute como a amizade adulta vem sendo empiricamente investigada no campo de estudos sobre relacionamentos sociais e pessoais em distintas áreas das ciências sociais e humanas. A produção brasileira

\section{Apoio: $\mathrm{CNPq} / \mathrm{Capes}$.}

* Doutora em Psicologia. Professora adjunta no Departamento de Psicologia da Universidade Federal de Minas Gerais, e colaboradora no Programa de Pós-Graduação em Psicologia da UFMG.

* Doutor. Professor titular da Universidade Federal do Rio Grande do Sul, e pesquisador no Programa de Pós-Graduação em Psicologia da UFRGS. 
sobre amizade em adultos é ainda incipiente e o presente artigo procura descrever os trabalhos publicados na área da psicologia e também em áreas afins.

Cientistas sociais vêm documentando há décadas os benefícios dos relacionamentos interpessoais. Estudos epidemiológicos demonstram que indivíduos socialmente integrados vivem mais (Fehr, 1996). Relacionamentos pessoais ou mais próximos - por exemplo, com familiares, amigos e parceiros românticos - atenuam a solidão e proporcionam bem-estar subjetivo, tendo, portanto, papel importante na felicidade pessoal e na promoção da saúde (Argyle, 2001; Berscheid \& Regan, 2005).

A partir do final do século XIX, o foco dos estudos em amizade passou das reflexões filosóficas e modelos antropológicos para investigações empíricas com crianças e adolescentes. Mais de um século de pesquisa sobre amizade na infância e adolescência permitiu construir um corpo de conhecimentos consistentes (Berndt, 1996; Bukowski, Newcomb \& Hartup, 1996); contudo, o estudo empírico e sistemático da amizade na vida adulta é bem mais recente, tendo iniciado na década de 1970 com as investigações sobre relacionamentos sociais e pessoais (Duck \& Perlman, 1985).

\section{RELACIONAMENTOS PESSOAIS E SOCIAIS: PASSADO E PRESENTE}

O esforço empírico sistematizado direcionado aos relacionamentos pessoais e sociais deve-se a um conjunto de fatores inter-relacionados. À insatisfação com as pesquisas conduzidas nos laboratórios de psicologia na década de 1970 somou-se uma demanda por investigações em ambiente natural, com o estudo de pessoas "reais". Um crescente interesse por estudos práticos e aplicados, como a investigação de habilidades sociais, promoção ou reparação de relacionamentos, solidão e violência doméstica, também estimulou o surgimento de novas pesquisas. Por fim, a preocupação com o desenvolvimento humano ao longo do ciclo vital incentivou o estudo dos relacionamentos nas diferentes etapas da vida e a análise desenvolvimental de relacionamentos de longa duração. A sistematização de trabalhos acadêmicos e práticos levou ao refinamento dos temas de investigação, da definição, tipos e propriedades dos relacionamentos, e conseqüentemente, as publicações que surgiram a partir de 1978 refletiram estas mudanças e influenciaram a produção científica da década seguinte (Duck \& Perlman, 1985).
Uma das mudanças mais significativas foi a definição de relacionamento como um processo dinâmico, que se desenvolve ao longo do tempo e se modifica conforme as etapas da vida, influenciado por normas sociais e aspectos culturais. Passou-se a reconhecer que um dado relacionamento, qualificado por seus integrantes como significativo na comparação com outros intercâmbios sociais, possui propriedades distintas daquelas identificadas separadamente em cada um dos indivíduos que nele interagem. Outro avanço na área foi o abandono do princípio de que a motivação para iniciar um relacionamento é atingir intimidade. "Muitos relacionamentos, talvez quase todos, existem em perfeita estabilidade sem serem íntimos ou sem muito desenvolvimento (da relação)" (Duck \& Perlman, 1985, p. 12) e, acima de tudo, são percebidos como satisfatórios para as pessoas envolvidas (Duck \& Perlman, 1985; Sarason, Sarason \& Pierce, 1995).

Uma década após a revisão de Duck e Perlman (1985), Sarason et al. (1995) apresentaram um novo panorama sobre o desenvolvimento teórico e empírico do estudo dos relacionamentos com ênfase na unidade de análise nas pesquisas. Três unidades de análise têm sido utilizadas: o indivíduo, a díade e o sistema. Com foco no indivíduo, estuda-se como ele percebe determinado relacionamento com outra pessoa, e como ele contribui para o desenvolvimento, a manutenção e o possível declínio da relação. As díades são analisadas correlacionando as percepções de ambos os indivíduos sobre o relacionamento; já os sistemas são estudados considerando não apenas as relações entre os integrantes da díade, mas também a interação desta com outras pessoas importantes de uma rede social mais ampla.

Dez anos após a revisão de Sarason et al. (1995), Berscheid e Regan (2005) realizaram uma avaliação do quadro teórico e empírico do campo dos relacionamentos interpessoais. Os autores concluíram que o corpo sistemático de conhecimento sobre relacionamentos interpessoais emergiu tardiamente não apenas em função da natureza multidisciplinar da ciência dos relacionamentos, mas também em virtude da dependência de avanços em outras ciências (sociais, comportamentais, biológicas). Até a década de 1950, por exemplo, a comunidade científica recusava o relacionamento como objeto de estudo em virtude de seu caráter "complexo e misterioso" (p. 65), inacessível à análise científica. Desafios éticos também se apresentavam na experimentação nesta área, porque o questionamento contínuo sobre os próprios relacionamentos poderia suscitar efeitos negativos ou inversos inesperados, por sugerirem aos 
participantes o que deveria ser tomado como "normal" ou "correto" com relação ao tema investigado.

Bell e Coleman (1999) entendem que o interesse pelo estudo da amizade enquanto relacionamento interpessoal ampliou-se consideravelmente. Segundo os autores, os contatos interpessoais têm se expandido para além do Mundo Ocidental, gerando a necessidade de constantes revisões nas regras e orientações para as interações. Assim, "o estudo da amizade pode nos forçar a criar novas questões sobre todos os aspectos culturais e sociais sob os quais vivemos e trabalhamos" (p. 5). Portanto, na visão de Bell e Coleman (1999), é pouco útil elaborar uma definição rígida de amizade, aplicável a todas as sociedades.

Reflexões sobre relacionamentos de amizade ocorrem na filosofia e nas ciências humanas desde a Antigüidade (Baldini, 2000); a produção científica, no entanto, embora recente, aponta um esforço para superar dificuldades conceituais e metodológicas anunciadas pela tradição de estudos com crianças e adolescentes.

\section{AMIZADE NA ADULTEZ: ASPECTOS CONCEITUAIS}

De um lado, a amizade é um relacionamento entre pessoas que não são familiares, parentes ou parceiras sexuais; de outro, estudos apontam cônjuges ou familiares como amigos (Fehr, 1996). Para Bell (1981), na amizade é fundamental a ausência de laços familiares, justificada pelas comparações e competições entre familiares e amigos e pela impossibilidade de escolha dos próprios familiares e parentes. Conseqüentemente, a amizade é um relacionamento pessoal e privado, sem a imposição de valores ou normas culturais. Esta visão difere da de culturas nas quais o envolvimento pessoal está sujeito às demandas institucionais da sociedade (Bell, 1981; Bell \& Coleman, 1999). Dessa forma, se a amizade fosse um relacionamento imune à cultura, não haveria pesquisas apontando sua influência na formação, desenvolvimento e manutenção das amizades (Blieszner \& Adams, 1992).

À primeira vista, Bell (1981) se opõe a Blieszner e Adams (1992) quanto ao papel de fatores sociais e culturais na definição da amizade; contudo, Bell considera que a igualdade social - que entende como equivalência socioeconômica - é fundamental. Ao mesmo tempo, também refere que a dedicação mútua nas trocas de qualquer natureza entre dois amigos deve ser igual, ampliando o significado de igualdade enquanto componente essencial das amizades.
Buscando uma definição de amizade que se afaste da mesma falta de consenso sobre relacionamentos (Duck \& Perlman, 1985; Sarason et al., 1995), Fehr (1996) considera-a "um relacionamento pessoal e voluntário, que propicia intimidade e ajuda, no qual as duas partes gostam uma da outra e buscam a companhia uma da outra" (p.7). Identificam-se aspectos similares aos apontados por Argyle (2001): em ajuda, visualiza-se a utilidade e a recompensa; em gostar um do outro e buscar sua companhia está o prazer e o companheirismo; e, em intimidade, o apoio emocional. Outros aspectos também vêm sendo abordados nas investigações: abertura, auto-revelação, autenticidade, aceitação, força de caráter, similaridades, compreensão, expressão dos sentimentos, dedicação mútua, altruísmo, reciprocidade, cuidado, confiança, compromisso, honestidade, facilidade de comunicação, aconselhamento, singularidade, duração da amizade, coexistência, tolerância, disponibilidade, respeito, confidência, espontaneidade, estabilidade, sucesso, contato físico, contato sexual, acessibilidade, interdependência, aparência física, habilidades sociais, responsividade, dependência, freqüência de contato, proximidade (closeness), autovalidação, conformidade ao grupo, autodefensividade e cooperação (Argyle \& Henderson, 1985; Bell, 1981; Cole \& Bradac, 1996; Davis \& Todd, 1985; Fehr \& LaGaipa, 1977; Maeda \& Ritchie, 2003; Mendelson \& Aboud, 1999; Monsour, 1992; Parks \& Floyd, 1996; Tesch \& Martin, 1983).

Duck e Perlman (1985) recomendaram que a pesquisa passasse a estudar os aspectos negativos nas amizades, visto que estes são inevitáveis e importantes para o desenvolvimento e manutenção dos relacionamentos. Nesta mesma direção, Berndt (1996) afirma que o exame das características da amizade lida com atributos interdependentes, ou seja, um interfere no outro. Assim, investigar aspectos positivos requer abordar fatores negativos. Bell (1981) havia indicado que a amizade pode envolver desaprovação e desafio ou questionamento regulares ao amigo pelo que ele é ou faz. Têm sido estudados fatores como ciúme, crítica em público, não defender o amigo na ausência deste, coerção, distanciamento emocional, abuso, violência, timidez, manejo de conflitos e tensões, sentimentos negativos, ansiedade e rivalidade (Argyle \& Henderson, 1985; Bukowski et al., 1996; Cole \& Bradac, 1996; Fehr, 1996; Maeda \& Ritchie, 2003; Koh, Mendelson \& Rhee, 2003).

Para Fehr (1996), embora seja preferível uma definição de amizade que se aplique a todo amigo, de qualquer cultura ou época, as concepções variam conforme idade, sexo, estado civil, religião, status 
profissional, escolaridade, etnia e raça. Dessa forma, a literatura apresenta dados sobre amizades de mesmo sexo, de sexo oposto, femininas, masculinas, infantis, de idosos, padres, militares, amizades mantidas a distância, etc. Outros estudos comparam amigos ocasionais, próximos, bons amigos, melhores amigos e amigos ideais.

Bell (1981) salienta a semelhança etária como um dos aspectos mais significativos na escolha das amizades, além do estado civil, da religião e do sexo. Pessoas da mesma faixa etária possuem recursos sociais e pessoais similares, o que previne contra a exploração de um sobre o outro. Divorciados sentem-se mais à vontade com amigos divorciados. Amizades de mesmo sexo previnem contra a possibilidade de romance, o que, conforme Bell, altera profundamente a amizade. Além disso, assim como há qualidades comuns entre mulheres, há aspectos compartilhados apenas por homens. Nas amizades entre casais, nota-se um vínculo maior entre as duas esposas e os dois maridos - um efeito conjunto de sexo com estado civil.

Dentre os modelos teóricos disponíveis para o estudo das amizades adultas, o de Fehr (1996) é bastante abrangente, contemplando muitas das variáveis tradicionalmente abordadas. Segundo a autora, as amizades se formam, desenvolvem e mantêm através da inter-relação de quatro conjuntos de fatores: fatores ambientais, situacionais, individuais e diádicos. Os fatores ambientais incluem proximidade residencial, local onde se passa o dia, densidade populacional e comunicação na rede social. Os fatores situacionais abrangem probabilidade de interação, freqüência de contato, dependência e disponibilidade. Com relação aos fatores individuais, primeiramente as pessoas selecionam de quem não é possível ser amigo (critérios de exclusão); posteriormente avaliam amigos em potencial (critérios de inclusão). Entre os critérios de exclusão identificados há o de desagrado e o baseado em diferenças (etárias, de raça, escolaridade, aparência física e de vestuário). Nos critérios de inclusão há aparência física, habilidade social, responsividade, timidez e similaridade. Por fim, há dois fatores diádicos no surgimento da amizade: o apreço mútuo no julgamento inicial de um indivíduo sobre o outro, e a auto-revelação (abertura para revelar assuntos particulares).

Os fatores situacionais, individuais, diádicos e ambientais são identificados nas amizades no contraste com pessoas não-amigas (embora não inimigas): estranhos, conhecidos e colegas. Amigos e não-amigos diferem quanto à interação verbal, à amplitude e profundidade das revelações nas conversas, e às semelhanças. Amigos dialogam mais, trocam mais abraços e beijos, revelam um maior número de assuntos e com mais profundidade, são parecidos quanto a traços de personalidade e atitudes, e se assemelham em sentimentos e gostos à medida que interagem (Fehr, 1996). Em contraste, entre pessoas conhecidas prevalece a superficialidade, dada a carência de revelações mútuas sobre si, de intimidade e de confiança - enfim, um não conhece o outro (Bell, 1981).

Relacionamentos estáveis ou em desenvolvimento são processos dinâmicos (Duck \& Perlman, 1985). Assim, a amizade está sujeita a constantes mudanças, especialmente por alterações não apenas em aspectos individuais ou em sua interação (aspectos diádicos), mas também por aquelas ocorridas à medida que se apresentam diferentes configurações situacionais ou ambientais. Amigos podem voltar a ser conhecidos ou até mesmo tornarem-se inimigos devido a mudanças de endereço, redução na freqüência de contato, competição ou ciúmes. Ao mesmo tempo, algumas amizades intensificam-se, o amigo ocasional tornandose melhor amigo.

\section{TIPOS E NÍVEIS DE AMIZADE}

A literatura empírica adota diferentes categorias para tipos e níveis de amizade. Fehr (1996), por exemplo, faz referência a amigo ocasional, amigo próximo e melhor amigo. Há também as categorias meio amigo (Wright, 1985); bom amigo (LaGaipa, 1977; Mendelson \& Aboud, 1999; Monsour, 1992); muito bom amigo (Mendelson \& Kay, 2003); o amigo mais próximo (Carbery \& Buhrmester, 1998); e amigo ideal (Cole \& Bradac, 1996; Maeda \& Ritchie, 2003). De outro lado, alguns trabalhos não diferenciam bons amigos de amigos próximos (Bell, 1981), ou amigos próximos de melhores amigos (Cole \& Bradac, 1996; Maeda \& Ritchie, 2003). Monsour (2002) deparou-se com muitos participantes de seu estudo sem melhores amigos, levando-o a usar a expressão "bons amigos".

Seja qual for a nomenclatura adotada, a diferença entre tipos e níveis de amizade é determinada por incrementos nas características a ela associadas (intimidade, apoio, auto-revelação) à medida que os amigos se tornam mais próximos. Assim, as diferenças são mais quantitativas do que qualitativas (Fehr, 1996). Conseqüentemente, no nível mais elevado de amizade encontrar-se-á maior aceitação, apoio, intimidade, etc., bem como maior durabilidade e freqüência de contato - nível chamado de melhor amizade ou de amizade próxima (Cole \& Bradac, 
1996; Davis \& Todd, 1985; Maeda \& Ritchie, 2003; Rezende, 2002; Wright, 1985).

Para Bell (1981), amigos próximos desenvolvem estilos semelhantes de voz, gestos, vestuário e comportamento; servem como proteção, facilitando a tolerância a medos e ansiedades e ajudando a suportar situações estressantes; e proporcionam um forte senso de identificação e exclusividade com experiências compartilhadas. Melhores amigos também tendem a morar perto um do outro (Fehr, 1996). Segundo Cole e Bradac (1996), a experiência real de ter um melhor amigo conduz a expectativas diferenciadas quanto à satisfação com esta amizade. Neste sentido, entende-se que onde a pesquisa sobre amizade na adultez estiver iniciando, como no Brasil, é mais apropriado conduzir primeiramente estudos sobre amizades reais para em um segundo momento investigar o ideal de amizade.

\section{AMIZADE E DESENVOLVIMENTO HUMANO}

As pessoas buscam relacionamentos motivadas por necessidades e preocupações vigentes em cada estágio da vida. Investigando estudantes de ensino médio, adultos recém-casados, adultos de meia-idade e adultos maduros sobre amizade real e ideal, Weiss e Lowenthal (1975) observaram que "as percepções das qualidades de amigos e da amizade são surpreendentemente semelhantes através dos quatro estágios de vida" (p. 58). As diferenças encontradas refletiam questões típicas enfrentadas pela fase. Por exemplo, as avaliações de amigos reais e ideais no ensino médio foram mais discrepantes, diminuindo com a idade e sugerindo maior seletividade nas escolhas de amigos em função da maturidade. Os autores concluíram que as funções básicas da amizade surgem cedo e permanecem ao longo da vida.

O uso da palavra amigo inicia aos quatro anos de idade; melhor amigo, a partir da infância média e adolescência. A amizade infantil caracteriza-se por afeto, divertimento e reciprocidades: mútua consideração, cooperação, bom manejo de conflito, benefícios equivalentes em trocas sociais; gostar um do outro, ou seja, desejar passar mais tempo na companhia prazerosa um do outro. As amizades de crianças mais velhas e adolescentes incluem lealdade, confiança e intimidade, requerem interesses comuns e comprometimento, tanto para manter os amigos como para formar novas amizades (Bukowski et al., 1996; Hartup, 1989).

Amizades adultas caracterizam-se por homogeneidade de traços de personalidade, interesses, sexo, idade, estado civil, religião, status ocupacional, etnia, renda, escolaridade, gênero, número de amigos, duração da amizade e tipos (Bell, 1981; Blieszner \& Adams, 1992; Fehr, 1996). A maioria das pesquisas aborda adultos jovens, geralmente estudantes universitários entre 18 e 30 anos. Esta tendência não decorre apenas da facilidade para coletar dados nas universidades, mas também do fato de que, nesta etapa, as amizades são mais evidentes. $\mathrm{Na}$ adolescência a amizade amadurece, passa a envolver confiança, lealdade e intimidade. Na adultez jovem, torna-se mais importante no contraste com o restante da vida adulta, que a restringe com demandas profissionais, românticas e familiares (Fehr, 1996; Rawlins, 1992).

Carbery e Buhrmester (1998) estudaram amigos próximos no contexto dos relacionamentos familiares na adultez jovem, dividindo-a em três fases: celibatária (na qual o indivíduo é solteiro e não está seriamente comprometido com um parceiro romântico), marital (relação conjugal sem filhos) e parental (com filhos pequenos). $\mathrm{Na}$ fase celibatária, os amigos são preferidos ao proverem apoio social, companheirismo e confidência; as mães, aliança e afeição. Na fase marital, o indivíduo depende mais do cônjuge para toda necessidade, especialmente o homem. $\mathrm{Na}$ fase parental, os filhos competem com o cônjuge no provimento de afeição, segurança e companheirismo. Assim, as amizades atingem o pico funcional da rede de relacionamentos no começo da adultez jovem (fase celibatária).

Segundo Rawlins (1992), a entrada na universidade requer do indivíduo um ajustamento emocional para construir um novo sistema de apoio social e renegociar relacionamentos familiares e amizades preexistentes. Este período de transição para a adultez é chamado de período universitário (17-22 anos), quando se vivenciam desafios e dúvidas sociais e intelectuais e uma grande expectativa quanto à vida pós-universitária. Assim, este período é favorável a amizades profundas e empolgantes. O relacionamento com os amigos é pouco influenciado por interações conjugais e familiares (Carbery \& Buhrmester, 1998; Rawlins, 1992). Destarte, está-se de acordo com Koh et al. (2003) ao argumentarem que a população de estudantes universitários é ideal para o estudo das amizades.

A entrada no mercado de trabalho, o casamento e os filhos tomam um tempo que antes era dedicado às amizades (Carbery \& Buhrmester, 1998; Koh et al., 2003; Monsour, 2002; Rawlins, 1992; Weiss e Lowenthal, 1975). Com o avanço etário, sente-se nostalgia dos amigos da juventude, como se a amizade transcendesse o tempo (Bell, 1981). 
O tempo livre pós-aposentadoria, a saída dos filhos de casa e as condições de saúde física e mental, finanças e moradia são aspectos cruciais à qualidade de vida na velhice (Castro, 2004), interferindo na formação e manutenção das amizades (Souza, 2004). Nesta etapa da vida, tem-se observado que a interação com amigos é menos freqüente, com encontros mais breves (Adams, Blieszner \& deVries, 2000). A convivência e o cultivo de amizades entre idosos têm se mostrado essenciais para a felicidade das pessoas dessa categoria, especialmente através da vivência diária em condomínios "segregados" (fechados) específicos para esta faixa etária (Debert, 1999). Além disso, as amizades na velhice são mais heterogêneas, devido à expectativa de vida (Blieszner \& Adams, 1992). De um lado, as amizades mais antigas são procuradas para troca de confidências, aconselhamento e relembrança de eventos passados em conjunto; de outro, as mais novas são valorizadas por oferecerem "um ponto de vista diferente" (Shea, Thompson \& Blieszner, 1988, p. 91).

\section{Estudos brasileiros sobre amizade em adultos}

Erbolato (2001) investigou as relações de amizade em 12 adultos jovens, 12 adultos em meia-idade e 12 idosos. A amizade foi relacionada a aspectos que foram comuns às três faixas etárias: satisfação de necessidades emocionais, troca de recursos e de comunicação, "estar presente", semelhanças, e facilidade de interação com o mundo. Especificamente com respeito aos adultos jovens (seis homens e seis mulheres de 25 a 35 anos de idade, inseridos no mercado de trabalho), o amigo foi definido através das seguintes características: segurança/proteção ( $40 \%$ das respostas) (por exemplo, saber ouvir e dizer coisas positivas, estar disponível para ajudar), seletividade/hierarquia (destaca-se das outras pessoas; há diferentes amigos conforme o nível de intimidade) e personalidade/autoconceito (como afinidades, amor e cuidado). A amizade foi apontada como importante porque responde a necessidades emocionais $(70 \%$ de respostas), é um relacionamento especial e faz parte da natureza humana.

Kipper (2003) discutiu a amizade no ambiente de trabalho em 60 adultos ( 27 homens e 33 mulheres, entre 20 e 50 anos de idade). A amizade foi mais definida em termos de companheirismo, de admiração e de orientação. No contexto do trabalho, parte dos participantes considerou que colegas de profissão são também amigos, na medida em que ajudam a suportar o ritmo de trabalho e a manter um ambiente bemhumorado (colegas-amigos). Para outro grupo de participantes, colegas são apenas colegas pela competitividade própria do ambiente de trabalho e pela falta de tempo para investir no relacionamento de amizade com um colega (colegas-colegas).

Rezende (2002) entrevistou 36 adultos divididos em dois grupos etários: de 20 a 30 anos e de 45 a 55 anos. A autora observou que o conceito de amigo se mostra amplo e indiferenciado fora do contraste com colegas. Esta oposição conduzia os participantes a definir amigo em termos de amigo próximo (amigo de verdade ou amigo mesmo); contudo, amizade comum envolve afeto, entendido através de aspectos como companhia agradável, sociabilidade, beijos, abraços e afagos. Entre os participantes mais jovens, as amizades ocorrem em grupos e com pouca variação nos programas (atividades) realizados em conjunto; já entre os mais velhos, as amizades interagem através de díades, com atividades mais variadas (diferentes díades para diferentes programas), com o amigo próximo freqüentando a casa. Não obstante, neste grupo o tempo dedicado ao lazer envolve mais a família do que os amigos. Rezende observou também que os relacionamentos entre "amigos mesmo" (amizade profunda ou verdadeira, segundo a autora) envolvem estilos de vida e valores semelhantes, troca de confidências e compartilhamento de experiências (intimidade), revelação e abertura, confiança (sinceridade, apoio mútuo), constante diálogo. Para tanto, é necessário um investimento considerável de tempo para o surgimento e desenvolvimento destes aspectos.

Nos três trabalhos descritos identificam-se atributos da amizade relatados na literatura internacional, como trocas afetivas, ajuda, companheirismo e diversão em certas atividades, intimidade e autovalidação. Também se pode observar a influência do ambiente de trabalho na formação de amizades e a consideração da passagem do tempo como aspecto fundamental em uma amizade próxima, melhor amizade ou amizade verdadeira.

\section{Diferenças de sexo nas amizades}

Evidências sugerem que as amizades entre mulheres são de melhor qualidade que entre homens, mais íntimas, próximas e divertidas, envolvendo maior satisfação e trocas afetivas. Amizades masculinas valorizam atividades conjuntas e são mais instrumentais, com ênfase no tempo investido na amizade (Carbery \& Buhrmester, 1998; Jones, 1991; Wright, 1988; Wright \& Scanlon, 1991). Para Fehr (1996), não se trata "de os homens não terem capacidade para intimidade, mas que, em vez disso, (eles) preferem não exercitá-la" (p. 153). Contudo, os resultados não são consensuais nas pesquisas. 
Na concepção de Wright (1988), as diferenças de sexo são supervalorizadas e ofuscam semelhanças entre amizades femininas e masculinas. Segundo Parks e Floyd (1996), a "feminização" da intimidade alcançou o pico na década de 1980, sob a influência do feminismo e da popularização de estudos como o de Carol Gilligan (citado por Parks \& Floyd, 1996) sobre diferenças de sexo no julgamento moral; assim, "tanto a literatura científica como a popular passou a argumentar, explicita ou implicitamente, que apenas as mulheres são capazes de intimidade" (p. 90). Esta argumentação será substituída pela ausência de vontade, por parte dos homens, de exercitar a intimidade (Fehr, 1996).

O pedido de Wright (1988) por moderação, cautela e ceticismo sobre diferenças de sexo em amizade vai redirecionar a produção científica subseqüente (Jones, 1991; Monsour, 1992; Parks \& Floyd, 1996; Wright \& Scanlon, 1991). Dois trabalhos ilustram esta mudança, argumentando que intimidade e proximidade são componentes essenciais das amizades adultas, que não há definições compartilhadas no meio acadêmico e que o tratamento científico destes aspectos é crucial à interpretação dos resultados (Monsour, 1992; Parks \& Floyd, 1996).

Monsour (1992) solicitou a 164 universitários que definissem intimidade (intimacy) na amizade com bons amigos do mesmo sexo ou do sexo oposto (que não fossem familiares ou parceiros românticos ou sexuais). Sete categorias de respostas emergiram da análise dos dados: auto-revelação, expressividade emocional, apoio incondicional, contato físico (abraços e beijos nas bochechas), confiança, atividades compartilhadas e contato sexual. A auto-revelação foi a mais freqüente tanto nas amizades de mesmo sexo como nas de sexo oposto, embora citada com mais freqüência nas amizades entre mulheres. Na interpretação do autor, mesmo que os resultados demonstrem a importância da auto-revelação na definição de intimidade na amizade de homens, ainda se trata de um componente menos central nas amizades masculinas do que nas femininas. De modo geral, os resultados permitiram observar que há mais semelhanças que diferenças nas amizades de mesmo sexo e de sexo oposto (Monsour, 1992).

Para Parks e Floyd (1996), Monsour (1992) não atentou para o conceito de proximidade, e, motivados por sua crítica, investigaram-na nas amizades de 270 universitários para diferenciá-la de intimidade e analisála quanto a diferenças de sexo. Parks e Floyd não encontraram referência a contato físico ou sexual. Proximidade mostrou-se um conceito mais abrangente que intimidade, abarcando aspectos não observados por Monsour como aceitação, compreensão, provisão de conselho e de perspectiva, freqüência de interação e duração da amizade.

Homens e mulheres diferem mais na definição de intimidade do que na de proximidade ao se referirem a boas amizades. Confirmou-se a importância da autorevelação nas amizades em geral, embora as mulheres a tenham citado mais que os homens. Observou-se também que, em boas amizades, de homens ou de mulheres, trocas afetivas, ajuda instrumental e aconselhamento, interesses e atividades compartilhados, confiança, freqüência de interação, duração, aceitação, respeito e contato físico nãosexual são fundamentais (Parks \& Floyd, 1996). Com base nestes dados, entende-se que estudos sobre diferenças de sexo devem considerar não apenas o sexo do participante, mas também o da amizade.

\section{CONSIDERAÇÕES FINAIS}

Sarason et al. (1995) propõem urgência na formulação de teorias específicas sobre os relacionamentos, pois esta medida contribuirá para o refinamento de construtos básicos ainda não satisfatórios por não serem consensuais na área. De outro lado, há o argumento de que as tentativas de formular uma teoria dos relacionamentos são prematuras, e que, embora contribuam para o avanço do campo, ainda não devem ser prioridade. Por ser demasiado recente (com pouco mais de 30 anos), a "nova ciência dos relacionamentos" (Duck \& Perlman, 1985 , p. 1) pode se beneficiar mais, por enquanto, do trabalho empírico. Ainda que o desenvolvimento teórico seja desejável, há fatores externos que nele interferem significativamente, como progressos da genética e sociobiologia, mudanças no papel da mulher e aumento do curso de vida (Sarason et al., 1995). À medida que a investigação empírica evoluir e possibilitar novos resultados e problemas de pesquisa, os modelos sobre relacionamentos disporão de mais recursos para a teorização.

Cabe ressaltar o apelo de Duck e Perlman (1985) por mais investigações sobre o que as pessoas pensam de seus relacionamentos. Assim, é preciso atentar para a instabilidade do pensamento sobre as interações significativas, visto que as pessoas pensam antes, durante e depois da interação, e em outras situações durante os intercâmbios posteriores. Para Duck e Perlman (1985), esta inconstância impede resultados claros e boas replicações.

Entende-se que dados obtidos sobre a amizade de brasileiros possam ser comparados a dados referentes a outras culturas e discutidos com base em modelos 
teóricos propostos; todavia, as possíveis diferenças decorrentes desta comparação devem ser estudadas, e não descartadas simplesmente para confirmar modelos da literatura internacional.

\section{REFERÊNCIAS}

Adams, R. G., Blieszner, R. \& deVries, B. (2000). Definitions of friendship in the third age: Age, gender, and study location effects. Journal of Aging Studies, 14(1), 117-133.

Argyle, M. (2001). The psychology of happiness. New York: Taylor \& Francis.

Argyle, M. \& Henderson, M. (1985). The rules of relationships. In S. Duck \& D. Perlman (Eds.), Understanding personal relationships (pp. 63-84). London: Sage.

Baldini, M. (2000). Amizade \& filósofos. Bauru: EDUSC.

Bell, R. (1981). Worlds of friendship. Beverly Hills: Sage.

Bell, S. \& Coleman, S. (1999). The anthropology of friendship: Enduring themes and future possibilities. In S. Bell \& S. Coleman (Eds.), The anthropology of friendship (pp. 1-19). Oxford: Berg.

Berndt, T. J. (1996). Exploring the effects of friendship quality on social development. In W. M. Bukowski, A. Newcomb \& W. Hartup (Eds.), The company they keep: Friendship in childhood and adolescence (pp. 346-365). Cambridge: University.

Berscheid, E. \& Regan, P. (2005). The psychology of interpersonal relationships. Upper Saddle River: Pearson.

Blieszner, R. \& Adams, R. G. (1992). Adult friendship. London: Sage.

Bukowski, W. M., Newcomb, A. F. \& Hartup, W. W. (Eds.). (1996). The company they keep: Friendship in childhood and adolescence. Cambridge: University.

Carbery, J. \& Buhrmester, D. (1998). Friendship and need fulfillment during three phases of young adulthood. Journal of Social and Personal Relationships, 15(3), 393-409.

Castro, O. (Org.). (2004). Envelhecer: revisitando o corpo. Sapucaia do Sul: Notadez.

Cole, T. \& Bradac, J. J. (1996). A lay theory of relational satisfaction with best friends. Journal of Social and Personal Relationships, 13(1), 57-83.

Daudt, P., Souza, L. K. \& Sperb, T. M. (2007). Amizade e gênero nos conflitos de pré-escolares. Interpersona: An International Journal on Personal Relationships, 1(1), 1-19.

Davis, K. E. \& Todd, M. J. (1985). Assessing friendship: Prototypes, paradigm cases and relationship description. In S. Duck \& D. Perlman (Eds.), Understanding personal relationships (pp. 1738). London: Sage.

Debert, G. G. (1999). A reinvenção da velhice: socialização e processos de reprivatização do envelhecimento. São Paulo: EDUSP/ FAPESP.

Duck, S. \& Perlman, D. (Eds.). (1985). Understanding personal relationships. London: Sage.

Erbolato, R. (2001). Contatos sociais: relações de amizade em três momentos da vida adulta. Tese de Doutorado Não-Publicada, Programa de Pós-Graduação do Instituto de Psicologia e
Fonoaudiologia, Pontifícia Universidade Católica de Campinas, Campinas.

Fehr, B. (1996). Friendship processes. London: Sage.

Garcia, A. (2005). Psicologia da amizade na infầncia: uma revisão crítica da literatura recente. Interação em Psicologia, 9(2), 285-294.

Hartup, W. (1989). Behavioral manifestations of children's friendships. In T. Berndt \& G. Ladd (Eds.), Peer relationships in child development (pp. 46-70). New York: Wiley.

Jones, D. C. (1991). Friendship satisfaction and gender: An examination of sex differences in contributors to friendship satisfaction. Journal of Social and Personal Relationships, $8(2), 167-185$.

Kipper, A. (2003). Sobre a amizade: relações de trabalho e bemestar subjetivo. Dissertação de Mestrado Não-Publicada, Programa de Pós-Graduação em Psicologia do Desenvolvimento, Universidade Federal do Rio Grande do Sul, Porto Alegre.

Koh, Y. J., Mendelson, M. J. \& Rhee, U. (2003). Friendship satisfaction in Korean and Canadian university students. Canadian Journal of Behavioural Science, 35(2), 239-253.

LaGaipa, J. (1977). Testing a multidimensional approach to friendship. In S. Duck (Ed.), Theory and practice in interpersonal attraction (pp. 249-270). London: Academic.

Lisboa, C. \& Koller, S. H. (2003). Amizade e vitimização: fatores de risco e proteção no contexto do grupo de iguais. PsicoPUCRS, 34(1), 71-94.

Maeda, E. \& Ritchie, L. D. (2003). The concept of shinyuu in Japan: A replication of and comparison to Cole and Bradac's study on U.S. friendship. Journal of Social and Personal Relationships, 20(5), 579-598.

Mendelson, M. J. \& Aboud, F. E. (1999). Measuring friendship quality in late adolescents and young adults: McGill Friendship Questionnaires. Canadian Journal of Behavioural Science, 31(2), 130-132.

Mendelson, M. J. \& Kay, A. (2003). Positive feelings in friendship: Does imbalance in the relationship matter? Journal of Social and Personal Relationships, 20(1), 101-116.

Monsour, M. (1992). Meanings of intimacy in cross- and same-sex friendships. Journal of Social and Personal Relationships, 9(2), 277-295.

Monsour, M. (2002). Women and men as friends: Relationships across the life span in the 21st century. Mahwah: Lawrence Erlbaum.

Parks, M. R. \& Floyd, K. (1996). Meanings for closeness and intimacy in friendship. Journal of Social and Personal Relationships, 13(1), 85-107.

Rawlins, W. K. (1992). Friendship matters. New York: Aldine de Gruyter.

Rezende, C. (2002). Os significados da amizade: duas visões de pessoa e sociedade. Rio de Janeiro: FGV.

Sarason, I., Sarason, B. \& Pierce, G. (1995). Social and personal relationships: Current issues, future directions. Journal of Social and Personal Relationships, 12(4), 613-619.

Shea, L., Thompson, L. \& Blieszner, R. (1988). Resources in older adults' old and new friendships. Journal of Social and Personal Relationships, 5(1), 83-96. 
Souza, L. K. (2004). Velho amigo, amigo velho: amizade na velhice. Em O. P. de Castro (Org.), Envelhecer: revisitando o corpo (pp. 69-86). Sapucaia do Sul: Notadez.

Souza, L. K., Gauer, G. \& Hutz, C. S. (2004). Publicações em psicologia do desenvolvimento em dois periódicos brasileiros na década de 1990. Psico-USF, 9(1), 49-57.

Tesch, S. A. \& Martin, R. R. (1983). Friendship concepts of young adults in two age groups. The Journal of Psychology, 115, 7-12.

Weiss, L. \& Lowenthal, M. (1975). Life-course perspectives on friendship. In M. Lowenthal, M. Thurnher, D. Chiriboga \& Assoc. (Eds.), Four stages of life: A comparative study of women and men facing transitions (pp. 48-61). San Francisco: Jossey-Bass.
Wright, P. (1988). Interpreting research on gender differences in friendship: A case for moderation and a plea for caution. Journal of Social and Personal Relationships, 5(3), 367-373.

Wright, P. (1985). The Acquaintance Description Form. In S. Duck \& D. Perlman (Eds.), Understanding personal relationships (pp. 39-62). London: Sage.

Wright, P. H. \& Scanlon, M. B. (1991). Gender role orientations and friendship: Some attenuation, but gender differences abound. Sex Roles, 24(9/10), 551-566.

Recebido em 04/04/2006 Aceito em 01/06/2006

\footnotetext{
Endereço para correspondência: Luciana Karine de Souza. Universidade Federal de Minas Gerais, FAFICH, Depto. de Psicologia, Av. Antonio Carlos, 6627, sala F-4050, Campus Pampulha, CEP 31.270-901, Belo Horizonte-MG.E-mail: lucianak@fafich.ufmg.br
} 